\title{
Historical perspectives of The American Association for Thoracic Surgery: Richard A. Jonas
}

\author{
Stephanie Fuller, MD, MS, and J. William Gaynor, MD
}

\author{
From the Division of Cardiothoracic Surgery, The Children's Hospital of Philadelphia, Philadelphia, Pa. \\ Disclosures: Authors have nothing to disclose with regard to commercial support. \\ Received for publication July 1, 2016; accepted for publication July 2, 2016; available ahead of print Aug 3, 2016. \\ Address for reprints: Stephanie Fuller, MD, MS, Division of Cardiothoracic Surgery, The Children's Hospital of \\ Philadelphia, 34th and Civic Center Boulevard, Philadelphia, PA 19104 (E-mail: fullers@email.chop.edu). \\ J Thorac Cardiovasc Surg 2016;152:1223-6 \\ $0022-5223 / \$ 36.00$ \\ Copyright (C) 2016 by The American Association for Thoracic Surgery \\ http://dx.doi.org/10.1016/j.jtcvs.2016.07.016
}

Richard Andrew Jonas was the 86th president of The American Association for Thoracic Surgery (AATS) and served from 2005 to 2006 (Figure 1). Reflecting on his international perspective as an Australian-American, he titled his address "Risks, rewards, and responsibilities of globalization for the cardiothoracic surgeon."1 As he began his address, he noted "This Association is a brilliant public symbol of the importance of the academic mission for the present and future of cardiothoracic surgery. By awarding

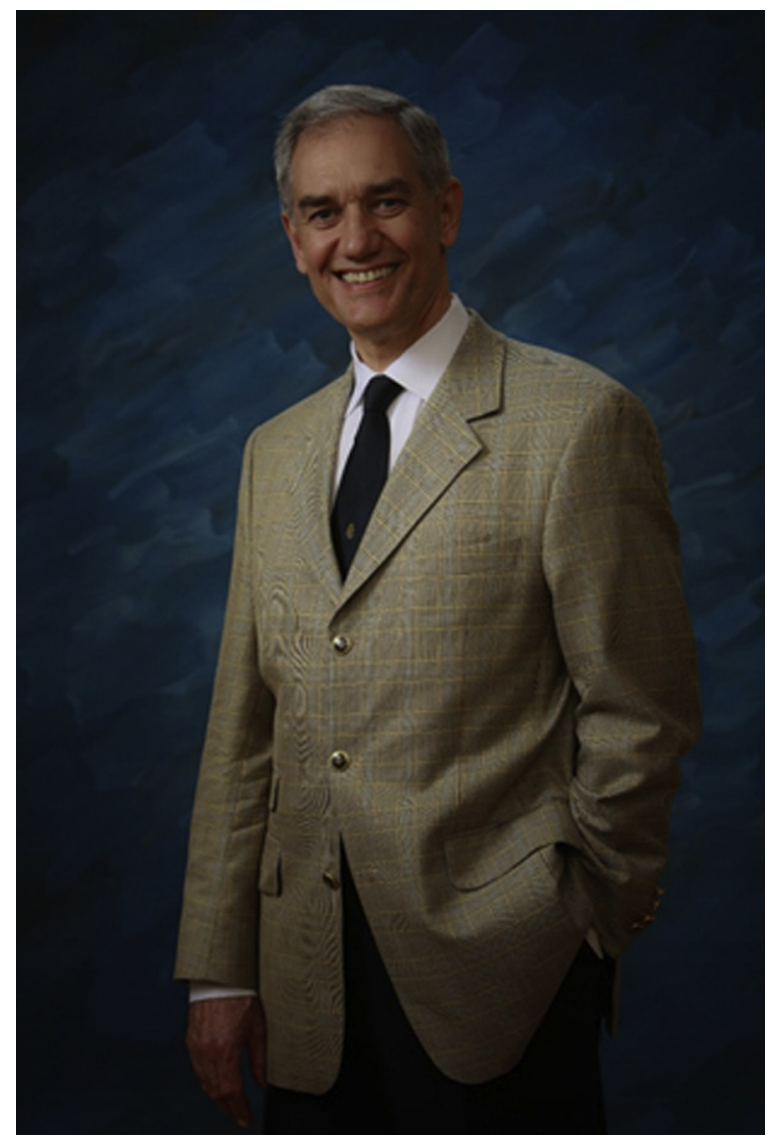

FIGURE 1. Dr Richard A. Jonas, 86th president of The American Association for Thoracic Surgery.

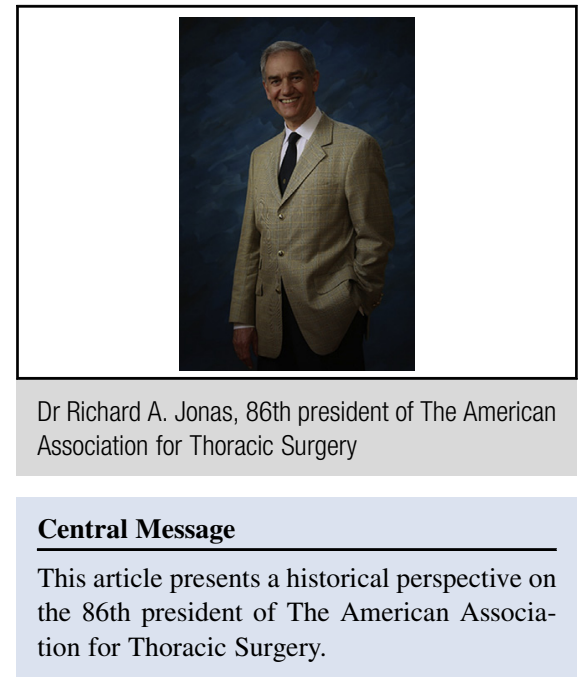

membership, the Association pays tribute through peer recognition to those who make significant contributions to teaching, research, and clinical surgery. When I became a member of the Association, I considered it one of the greatest honors of my professional career.",

Dr Jonas was born and raised in Adelaide, South Australia, on the south-central coast of Australia. Reflecting the early demographics of South Australia, Dr Jonas's maternal and paternal forebears migrated to Australia in the mid-1800s from southern England and northern Germany. They included the Bristow family descended from John Bristow, a distinguished 19th century surgeon at $\mathrm{St}$ Thomas' Hospital, London, whose portrait hangs today in the committee room at St Thomas' (Figure 2). Lyall Jonas, Richard's father, was one of the youngest commanders of an Australian naval vessel in the Second World War, laying mines in the treacherous seas south of New Guinea. After the war he returned to Adelaide where he took over the family shipping business with his 2 cousins and expanded into mining. Richard's mother, June Clio Coles-Robinson, played a role in the establishment of Adelaide's first hospital for children with cerebral palsy.

Dr Jonas attended St. Peter's College in Adelaide, a prestigious Anglican boarding college with many notable alumni including 3 Nobel Laureates: Sir Lawrence Bragg (Physics 1915), Howard Florey (Medicine 1945), and Robin Warren (Medicine 2005). He excelled academically in the highly competitive environment at St. Peter's, winning almost every one of the coveted awards for academic 

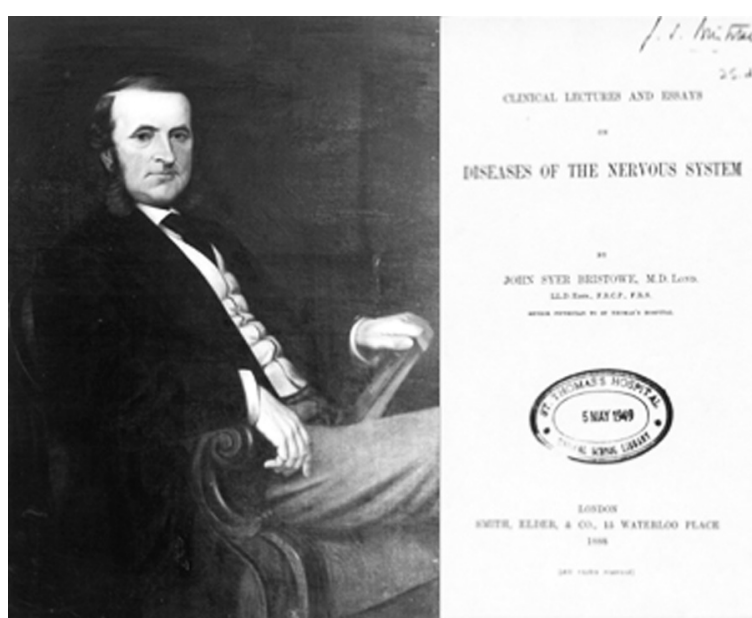

FIGURE 2. Dr Jonas's paternal grandmother Marjorie Fricker-Bristow was a descendant of John Bristow, a surgeon at St Thomas' London in the mid-1800s.

excellence (Figure 3). Richard graduated from St. Peter's in 1968 and entered medical school at Adelaide University with the goal of becoming a medical researcher. However, he was soon inspired at medical school to enter the field of surgery, specifically heart surgery through the influence of Hamilton D'Arcy Sutherland, chief of cardiothoracic surgery at the Royal Adelaide Hospital. On graduation with honors in 1974, he moved to Melbourne to train in general surgery at the Royal Melbourne Hospital, Australia's preeminent surgical institution.

In 1979, on completion of his general surgical training, Dr Jonas was invited by Dr D'Arcy Sutherland to begin training in cardiothoracic surgery at the Royal Children's Hospital in Melbourne. Dr Sutherland had recently become executive director of the Royal Australasian College of Surgeons and had moved from Adelaide to reinvigorate pediatric cardiac surgery at Australia's leading pediatric hospital in Melbourne. Dr Roger Mee was recruited from Boston Children's Hospital and established the Royal Children's Hospital as one of the leading centers in the world for primary repair of complex congenital heart anomalies. Coincidentally that year, when Drs Mee and Jonas began working at Royal Children's, prostaglandin E1 was widely introduced, opening the door to corrective neonatal surgery.

Dr Mee arranged for Richard to move to the Green Lane Hospital in Auckland on completion of his year at the Royal Children's Hospital. At Green Lane Hospital in New Zealand, Richard trained in general cardiothoracic, vascular, and congenital cardiac surgery. In particular he was exposed to Sir Brian Barratt-Boyes, KBE, who emphasized the importance of early primary repair of congenital anomalies. It was during this period in the early 1980s that BarrattBoyes was working closely with Dr John Kirklin (59th president of the AATS) from the University of Alabama

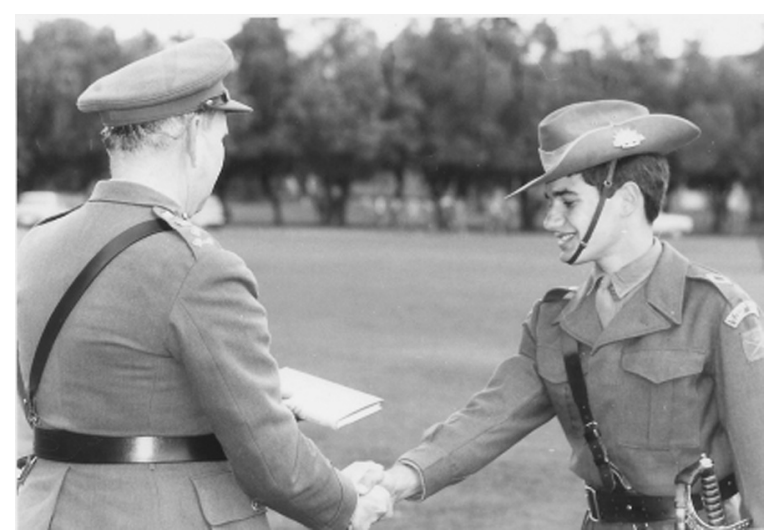

FIGURE 3. Dr Jonas receives the General Rowell Trophy for the most outstanding army cadet in the state of South Australia, 1968.

Birmingham (UAB), co-writing the great textbook of cardiac surgery that was to become the foundation of the entire field of cardiac surgery for the next few decades. After Richard completed certification in cardiothoracic surgery with the Australasian College of Surgeons in 1982, BarrattBoyes arranged for him to take a fellowship position at the Brigham and Women's Hospital in Boston.

At the Brigham and Women's Hospital, Dr Jonas worked with Drs Lawrence Cohn (79th president of the AATS), Jack Collins, and Richard Shemin, and was exposed to the efficiency and superb high standards of the US health care system. At the end of 1982 he rotated to Boston Children's Hospital to work with Drs Aldo Castaneda (74th president of the AATS) and William I. Norwood, initially as a senior fellow and subsequently as chief resident. In January 1983, Dr Norwood published the first report of successful surgical palliation of hypoplastic left heart syndrome. Also that month, Drs Norwood and Castaneda performed the world's first successful neonatal arterial switch procedures. Exposure to these 2 seminal events was pivotal in Dr Jonas's career and signified that congenital heart surgery had evolved to the point where the goal of corrective surgery as early in life as possible had been realized.

When Dr Norwood left for The Children's Hospital of Philadelphia at the end of 1983, Dr Jonas was invited by Dr Castaneda join him at Boston Children's Hospital. Dr Jonas soon acquired a large experience with the Norwood operation and published early reports describing the technical challenges this procedure raised. Drs John Mayer and Frank Hanley were surgical partners in Boston. In 1994, Dr Jonas was appointed as the William E. Ladd Professor of Child Surgery at the Harvard Medical School and Surgeon-in-Chief of the Department of Cardiac Surgery at Boston Children's Hospital. Dr Pedro del Nido (95th president of the AATS) was recruited from Pittsburgh to join the faculty. The program continued to grow in size and prestige, including the continuing expansion of the highly innovative 
interventional cardiology program directed by Dr Jim Lock. Numerous graduates of the extensive cardiac surgical training program have gone on to lead programs around the country and around the world. In 2004, after 22 years in Boston, Richard was recruited to expand the clinical and laboratory research programs in cardiac surgery at the Children's National Medical Center in Washington, DC.

While developing an extremely productive clinical career, Dr Jonas began a program of investigation into the neurologic complications of cardiopulmonary bypass, specifically of deep hypothermic circulatory arrest. This has been one of his most important contributions to the field. In the late 1980s, he worked with research psychologist Dale Corbett, $\mathrm{PhD}$, who examined the development of animal models of ischemic brain injury. These studies suggested that techniques of bypass were suboptimal, including rapid cooling with severe hemodilution and alkalosis. An epidemic of choreoathetosis in the late 1980s at Boston Children's led to retrospective studies and subsequently prospective trials to elicit the causes. Working in conjunction with Dr Jane Newburger and the renowned developmental psychologist Dr David Bellinger, Dr Jonas began to study, in a systematic fashion, the potential risk factors for brain injury and neurodevelopmental disability after cardiac surgery in neonates. This collaboration was incredibly productive and lead to the Boston Circulatory Arrest Study, a landmark in the field of congenital heart surgery. ${ }^{2-4}$ A study of hemodilution was terminated early by the National Institutes of Health (NIH) when it was found that the current recommended and widely followed practice of hemodiluting to a hematocrit of $20 \%$ was associated with important motor deficits. ${ }^{5}$ This clinical trial led to a worldwide shift in the technique of cardiopulmonary bypass for neonates and infants. When in DC he also established an NIH-supported laboratory that works closely with the outstanding neuroscience research group led by Vittorio Gallo, PhD. His laboratory director Nobu Ishibashi is conducting groundbreaking studies of cellular mechanisms of cerebral white matter injury.

Dr Jonas has been prolific as an academician and teacher. Dr Kirklin invited him to participate as a co-author in the second edition of his textbook Cardiac Surgery. At about the same time in the early 1990s, Castaneda and the team at Boston Children's put together their highly successful textbook Cardiac Surgery of the Neonate and Infant. Dr Jonas also worked with Dr Martin Elliott from Great Ormond Street Hospital for Sick Children London to co-edit a new textbook Cardiopulmonary Bypass for Neonates, Infants and Children. A subsequent textbook, Brain Injury and Pediatric Cardiac Surgery, included contributions by many of the most important researchers in the field at that time. In 2004, Dr Jonas wrote and published Comprehensive Surgical Management of Congenital Heart Disease. A second edition was published in 2014 that includes an e-version with more than 50 streaming videos.

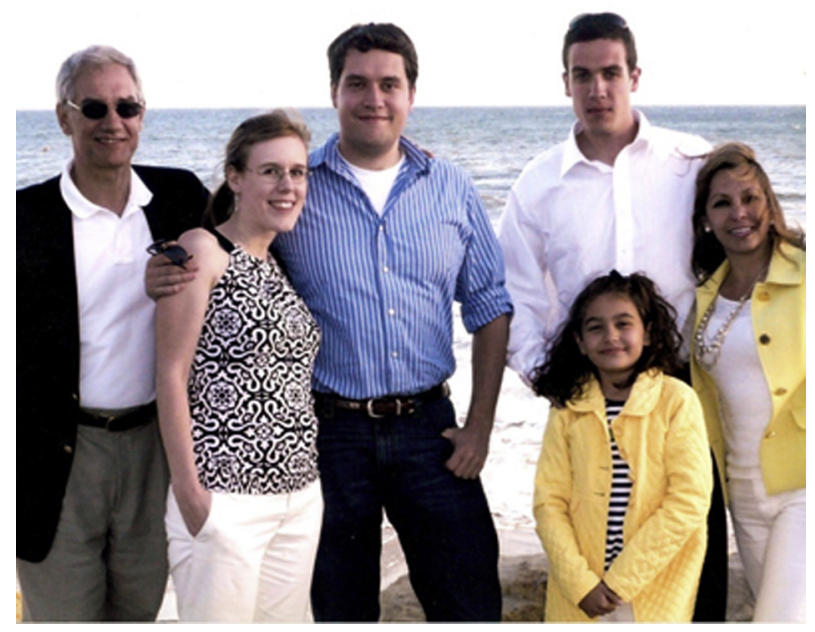

FIGURE 4. The Jonas family (from left to right) Richard, a family friend, Andrew, Michael, Nicole Sofia, and Katherine.

Richard is a long-standing member of the Congenital Heart Surgeons Society. He played a pivotal role as secretary during the transition of the data center from $\mathrm{UAB}$ to Toronto in the early 2000s; as well as incorporation of the society as a $501 \mathrm{C} 3$ and management by PRRI. He was president of the society from 2008 to 2010. In 2007, he hosted the inaugural meeting of the World Society for Pediatric and Congenital Heart Surgery in Washington, DC, and was a member of the Constitutional Council. As chair of the publications committee, he was instrumental in establishing the World Journal for Pediatric and Congenital Heart Surgery, the first journal entirely devoted to the field. He will become president of the society in 2016.

Another significant contribution by Dr Jonas is his attention to the inequity of services of congenital heart surgery and the unmet needs of underserved populations, which he emphasized in his presidential address. In 1984, just as he started on staff at Boston Children's Hospital, Richard was invited by Project Hope to develop a pediatric heart surgery program in Shanghai, China. In March 1986, after 2 years devoted to fund raising and team building, Dr Jonas led a team of 15 professionals to Shanghai. There were many challenges teaching infant heart surgery in a setting of unreliable power, steam, and even water supply. He returned to Shanghai annually for many years, sometimes staying for 3 to 4 weeks. The program grew rapidly, requiring the building of a new pediatric hospital in Pudong, and today this program is probably the busiest in the world with more than 3500 pump cases annually.

Despite a heavy clinical workload and the demands of an NIH-supported laboratory, Dr Jonas has always been closely involved in the upbringing of his 3 children (Figure 4). At their vacation home in the White Mountains of New Hampshire they spend time together skiing in winter 
and on Lake Winnipesaukee in the summer. Andrew is a senior software engineer in Boston, Michael is in property management in Breckenridge, Colorado, and Nicole Sofia is a chorister with the National Cathedral Choir in Washington, DC. Richard's wife Katherine Vernot-Jonas is an architect and interior designer in Georgetown and is active in fund raising for the Children's National Medical Center and the Women's Board of the American Heart Association.

\section{References}

1. Jonas RA. Rewards, risks, and responsibilities of globalization for the cardiothoracic surgeon. J Thorac Cardiovasc Surg. 2007;134:1-14.
2. Bellinger DC, Jonas RA, Rappaport LA, Wypij D, Wernovsky G, Kuban KC, et al. Developmental and neurologic status of children after heart surgery with hypothermic circulatory arrest or low-flow cardiopulmonary bypass [see comment]. N Engl J Med. 1995;332:549-55.

3. Bellinger DC, Wypij D, Rivkin MJ, DeMaso DR, Robertson RL Jr, DunbarMasterson C, et al. Adolescents with d-transposition of the great arteries corrected with the arterial switch procedure: neuropsychological assessment and structural brain imaging. Circulation. 2011;124:1361-9.

4. Newburger JW, Jonas RA, Wernovsky G, Wypij D, Hickey PR, Kuban KC, et al. A comparison of the perioperative neurologic effects of hypothermic circulatory arrest versus low-flow cardiopulmonary bypass in infant heart surgery [see comment]. N Engl J Med. 1993;329:1057-64.

5. Jonas R, Wypij D, Roth S, Bellinger D, Visconti K, du Plessis A, et al. The influence of hemodilution on outcome after hypothermic cardiopulmonary bypass: results of a randomized trial in infants. J Thorac Cardiovasc Surg. 2003;126: $1765-74$. 